\title{
CLINICAL PROFILE AND ETIOLOGICAL EVALUATION OF NON-TRAUMATIC MYELOPATHIES USING MAGNETIC RESONANCE IMAGING
}

\author{
BIJAYA KUMAR BEHERA ${ }^{1 *}$, SUKANTA KUMAR JENA ${ }^{2}$, NISARG BEHERA ${ }^{3}$
}

${ }^{1}$ Department of General Medicine, MKCG Medical College and Hospital, Berhampur, Odisha, India. ${ }^{2}$ Department of Radiodiagnosis, MKCG Medical College and Hospital, Berhampur, Odisha, India. ${ }^{3}$ Department of General Medicine (Intern), MKCG Medical College and Hospital, Berhampur, Odisha, India. Email: drbkbehera@gmail.com

Received: 18 March 2021, Revised and Accepted: 15 May 2021

ABSTRACT

Objective: The present study was conducted with an objective to identify the etiology of non-traumatic myelopathies of both compressive and noncompressive types with the aid of magnetic resonance imaging (MRI).

Methods: This retrospective observational cross-sectional study was conducted on 100 patients with a clinical diagnosis of non-traumatic myelopathy belonging to the age group of 15-75 years from August 2018 to July 2020 in the Departments of General Medicine and Radiodiagnosis of MKCG Medical College and Hospital, Berhampur, Odisha. Detailed history, clinical evaluation, laboratory investigations, and findings of MRI spine and brain were compiled. Results were analyzed using descriptive statistics.

Results: Among 100 patients of non-traumatic myelopathy, 65 patients presented with compressive myelopathy and 35 patients with non-compressive myelopathy where 56 patients presented with paraparesis and 44 with quadriparesis. Pott's spine $(n=25,38.46 \%)$ and acute transverse myelitis (ATM) $(n=24,68.57 \%)$ were the most common etiologies found in compressive and non-compressive groups, respectively.

Conclusion: Pott's Spine, spondylotic myelopathy, and ATM were the most common etiologies of non-traumatic myelopathy. MRI has proven to be the ultimate imaging modality for their etiological evaluation.

Keywords: Non-traumatic myelopathy, Compressive myelopathy, Non-compressive myelopathy, Magnetic resonance imaging.

(C) 2021 The Authors. Published by Innovare Academic Sciences Pvt Ltd. This is an open access article under the CC BY license (http://creativecommons.org/ licenses/by/4.0/) DOI: http://dx.doi.org/10.22159/ajpcr.2021v14i7.41487. Journal homepage: https://innovareacademics.in/journals/index.php/ajpcr

\section{INTRODUCTION}

Myelopathy describes any neurologic deficit related to the spinal cord [1]. It can be either traumatic or non-traumatic. Non-traumatic spinal cord diseases constitute one of the most common groups of neurological diseases in medical practice [2]. It is a broad and heterogeneous group of etiologies, summarily divided into compressive and non-compressive diseases [3], which include vertebral spondylosis, neoplasm, infections, vascular ischemia, multiple sclerosis (MS), motor neuron disease, radiation myelopathy, syringomyelia, paraneoplastic syndrome, and Vitamin $B_{12}$ deficiency.

Spinal cord diseases often have devastating consequences, ranging from quadriplegia and paraplegia to severe sensory deficits. Many of these diseases are potentially reversible if recognized and treated at an early stage. Thus, they are among the most critical neurologic emergencies, where prognosis depends on an early and accurate diagnosis [4].

Clinically, the diagnosis of myelopathy depends on the neurologic localization of the finding to the spinal cord, rather than the brain or peripheral nervous system and then to a particular segment of the spinal cord. The antecedent clinical syndrome and other details of the patient's course are helpful, but imaging plays a crucial role [1].

The incidence, demographics, clinical presentations, and outcomes for the non-traumatic spinal cord injury/disease (SCI/D) population have not been as thoroughly studied as in persons with traumatic SCI [5].

Magnetic resonance imaging (MRI) is the mainstay in evaluation of myelopathy. It has improved imaging of the spinal cord lesions to a point that reliable diagnosis of even a non-expansible lesion is routinely possible [6].
The present study was aimed at evaluating the clinical profile and etiology of non-traumatic myelopathies with the aid of MRI.

\section{METHODS}

This retrospective observational cross-sectional study was conducted on 100 patients of non-traumatic myelopathy admitted in the medical and neurology wards of MKCG Medical College and Hospital, Berhampur, Odisha, from August 2018 to July 2020. Information on routine and laboratory tests of patients such as complete blood count, serum urea, serum creatinine, fasting blood sugar, liver function tests, electrocardiography, Mantoux test, erythrocyte sedimentation rate, chest X-ray, plain X-ray of spine, and specific investigations such as collagen profile serum Vitamin $B_{12}$, serum HIV, ultrasonography of abdomen and pelvis, cerebrospinal fluid analysis, and nerve conduction study were compiled. MRI spine and MRI brain study findings were collected from the department of radiodiagnosis.

\section{Inclusion criteria}

Patients of both sexes and greater than 15 years of age with symptomatic cases of non-traumatic paraparesis and quadriparesis were included in this study.

\section{Exclusion criteria}

Cases with contraindication for MRI (such as prosthetic heart valve, implanted pacemaker, or any other orthopedic metallic implant) were excluded from this study.

\section{Statistical analysis}

Results were analyzed using Microsoft Excel 2010 using descriptive statistical tools such as frequencies, mean, \pm standard deviation (SD), and percentages. 


\section{RESULTS}

Out of 100 patients of non-traumatic myelopathy, 57 were male and 43 were female with an age group of 15-75 years and a male-to-female ratio 1.33:1 (Table 1). In this study, maximum number of patients (30\%) was in the age group of $46-55$ years followed by $21 \%$ in the age group of $36-45$ years.

The mean $( \pm \mathrm{SD})$ age of the study population was $44.75( \pm 13.88)$ years.

Out of 100 cases, number of compressive myelopathy was 65 and noncompressive myelopathy was 35 (Table 2).

Majority of patients of compressive myelopathy group were presented with paraparesis $(n=36,55.38 \%)$, whereas 29 (44.62\%) patients were presented with quadriparesis. Patients presenting paraparesis and quadriparesis in non-compressive group were 20(57.14\%) and 15 (42.86\%), respectively (Table 2).

Etiologies of compressive myelopathy in the above study were found to be Pott's spine $(n=25,38.46 \%)$, spondylotic myelopathy $(n=23$, $35.38 \%)$, tumors ( $n=9,13.85 \%)$, CV junction anomalies $(n=4,6.15 \%)$, multiple myeloma $(n=2,3.08 \%)$, syringomyelia $(n=1,1.54 \%)$, and epidural abscess $(n=1,1.54 \%)$ (Table 3$)$.

Etiologies of non-compressive myelopathy were found to be acute transverse myelitis (ATM) $(n=24,68.57 \%)$, subacute combined degeneration $(n=5$, $14.29 \%), M S(n=4,11.43 \%)$, acute disseminated encephalomyelitis (ADEM) ( $\mathrm{n}=1,2.86 \%$ ), and HIV myelopathy ( $\mathrm{n}=1,2.86 \%$ ) (Table 4).

Pott's spine $(n=25,38.46 \%)$ and ATM $(n=24,68.57 \%)$ were the most common etiologies found in the compressive and non-compressive group, respectively. The study also observed that in Pott's spine, 25 (100\%) patients had paraparesis, 21 (84\%) patients had sensory symptoms, and $15(60 \%)$ had bowel and bladder involvement. In spondylotic myelopathy $(\mathrm{n}=23), 20(86.95 \%)$ patients presented with quadriparesis and most patients $(\mathrm{n}=21,91.3 \%)$ had sensory symptoms and 9 (39.13\%) patients had involvement of bowel and bladder. Out of 24 patients with ATM, $14(58.33 \%)$ were presented with paraparesis and 10 (41.66\%) with quadriparesis, 18 (75\%) patients had sensory symptoms, and 14 (58.33\%) had bowel and bladder involvement. Among the nine cases of spinal tumor, $6(66.66 \%)$ presented with paraparesis, $6(66.66 \%)$ were having sensory symptoms, and 5 (55.55\%) had bowel and bladder involvement.

Thirty-seven patients were presented with acute onset of illness, 21 with subacute onset while the remaining 42 patients had a chronic presentation of illness.

Table 1: Age and gender distribution $(n=100)$

\begin{tabular}{lllll}
\hline $\begin{array}{l}\text { Age group } \\
\text { in years }\end{array}$ & $\begin{array}{l}\text { Males, } \\
\mathbf{n = 5 7}\end{array}$ & $\begin{array}{l}\text { Females, } \\
\mathbf{n = 4 3}\end{array}$ & $\begin{array}{l}\text { Total, } \\
\mathbf{n = 1 0 0}\end{array}$ & Percentage \\
\hline $15-25$ & 5 & 4 & 9 & 9 \\
$26-35$ & 11 & 8 & 19 & 19 \\
$36-45$ & 10 & 11 & 21 & 21 \\
$46-55$ & 18 & 12 & 30 & 30 \\
$56-65$ & 8 & 5 & 13 & 13 \\
$66-75$ & 5 & 3 & 8 & 8 \\
Total & 57 & 43 & 100 & 100 \\
\hline
\end{tabular}

Mean \pm SD (range): $44.75( \pm 13.88)$

Table 2: Clinical presentation of compressive and non-compressive myelopathy group $(n=100)$

\begin{tabular}{|c|c|c|c|c|c|}
\hline \multirow[t]{2}{*}{$\begin{array}{l}\text { Clinical } \\
\text { presentation }\end{array}$} & \multicolumn{2}{|c|}{ Compressive, $n=65$} & \multicolumn{2}{|c|}{$\begin{array}{l}\text { Non-compressive, } \\
n=35\end{array}$} & \multirow[t]{2}{*}{$\begin{array}{l}\text { Total, } \\
\mathbf{n = 1 0 0}\end{array}$} \\
\hline & Number & $\%$ age & Number & $\%$ age & \\
\hline Paraparesis & 36 & 55.38 & 20 & 57.14 & 56 \\
\hline Quadriparesis & 29 & 44.62 & 15 & 42.86 & 44 \\
\hline Total & 65 & 100 & 35 & 100 & 100 \\
\hline
\end{tabular}

Various locations of the lesions found in our study involved lumbar, dorsolumbar, dorsal, cervicodorsal, and cervical where cervical lesions were found in maximum number of patients (39\%).

The dorsal spine was most frequently affected by tuberculosis. The most common site of involvements for cervical spondylotic myelopathy were cervical C4/C5 and C5/C6, whereas for ATM, the common site of involvement was dorsal spinal segment.

Out of nine cases with tumors, three cases had intramedullary and six cases had extramedullary-intradural lesions.

\section{DISCUSSION}

Rapid diagnosis and early treatment of non-traumatic myelopathy are crucial determinants of long-term recovery and favorable prognosis of a patient. Therefore, the treating physician has to be well acquainted with various clinical presentations and diagnostic aids for nontraumatic myelopathy [7]. Very limited statistical data are available on this incidence. The present study was aimed at investigating the clinical and etiological profile of non-traumatic myelopathy.

In 2013, the World Health Organization reported that the incidence of non-traumatic myelopathies was higher in male than in females and incidence steadily increased with age [8]. The present study shows a similar result where male and female percentages were $57 \%$ and $43 \%$, respectively (Table 1). Similar findings were observed in studies done by Haleem et al. [9] in Bangladesh, where $62 \%$ were male and 38\% were female and the highest number of patients was in the age group of 51-60 years which correlates to the present study of maximum number of patients in the age group of 56-65 years (Table 1 ).

The present study observed that $65 \%$ of cases had compressive myelopathy and $35 \%$ had non-compressive myelopathy which is similar to the study of Chaurasia et al. [10], where out of 204 patients, former cases were found to be $62 \%$ and the later to be $38 \%$ (Table 2).

Pott's spine ( $n=25,38.46 \%$ ) was the most common cause of compressive myelopathy in the present study followed by spondylotic myelopathy $(n=23,35.38 \%)$ (Table 3) which correlates well with various Indian studies [10-12]. All the patients of Pott's spine in our study were having paraparesis where it was found to be $93.3 \%$ in the study of Chaurasia et al. and $91.7 \%$ in the study of Haleem et al. A similar observation has been found by Deivigan et al. [13]. In our study, bladder-bowel was found to be involved in $52 \%$ of cases whereas $80 \%$ of cases had sensory symptoms. Similar findings have been observed in cases of Haleem et al.

MRI suggested most common sites of involvement were at T(7-10). Pott's spine featured signal intensities appearing hypointense on T1W and hyperintense on $\mathrm{T} 2 \mathrm{~W}$ sequences with heterogeneous enhancement of the vertebral body. MRI plays an important role in the diagnosis of spinal TB with a high specificity and sensitivity [14].

Spondylotic myelopathy was the second most common cause of compressive myelopathy in the present study group, incidence being $35.38 \%$. Out of 23 patients, $20(86.95 \%)$ patients were presented with quadriparesis and three patients with paraparesis. Most of the patients presented with disc degeneration, stenosis, osteophyte formation at the level of facet joints, and segmental ossification of the posterior longitudinal ligament. Twelve $(52.17 \%)$ patients had multiple levels of involvement (C3-C8). Most frequent levels of involvement were seen at C4-C5 and C5C6. One hundred and seventy-three patients of Nagata et al. [15] study with cervical myelopathy observed the most frequent levels of involvement at C3-C4, C4-C5, and C5-C6. MRI findings such as disc protrusion, abutting and flattening the ventral cord surface, and intramedullary high signal intensity on T2WI in the spinal gray matter causing cord deformity with associated cord edema confirmed the diagnosis in our study.

The third most common cause of non-traumatic compressive myelopathy was tumor $(\mathrm{n}=9,13.85 \%)$. Studies from Chaurasia et al. 
Table 3: Etiological diagnosis and clinical profile of non-traumatic compressive myelopathy $(n=65)$

\begin{tabular}{|c|c|c|c|c|c|c|}
\hline \multirow[t]{3}{*}{ Etiological profile } & \multicolumn{6}{|c|}{ Clinical profile } \\
\hline & \multicolumn{2}{|c|}{ Quadriparesis, n=29 } & \multirow{2}{*}{$\begin{array}{l}\text { Paraparesis, n=36 } \\
\text { Number }\end{array}$} & \multicolumn{3}{|c|}{ Total, $n=65$} \\
\hline & Number & $\%$ age & & $\%$ age & Number & $\%$ age \\
\hline Pott's spine & 0 & 0 & 25 & 38.46 & 25 & 38.46 \\
\hline Spondylotic myelopathy & 20 & 30.77 & 3 & 4.62 & 23 & 35.38 \\
\hline Tumors & 3 & 4.62 & 6 & 9.23 & 9 & 13.85 \\
\hline CV junction anomaly & 4 & 6.15 & 0 & 0 & 4 & 6.15 \\
\hline Epidural abscess & 1 & 1.54 & 1 & 1.54 & 2 & 3.08 \\
\hline Syringomyelia & 1 & 1.54 & 0 & 0 & 1 & 1.54 \\
\hline Multiple myeloma & 0 & 0 & 1 & 1.54 & 1 & 1.54 \\
\hline Total & 29 & 44.62 & 36 & 55.38 & 65 & $100 \%$ \\
\hline
\end{tabular}

Table 4: Etiological diagnosis and clinical profile of non-traumatic non-compressive myelopathy (n=35)

\begin{tabular}{|c|c|c|c|c|c|c|}
\hline \multirow[t]{3}{*}{ Etiological profile } & \multicolumn{6}{|c|}{ Clinical profile } \\
\hline & \multicolumn{2}{|c|}{ Quadriparesis, $n=15$} & \multicolumn{2}{|c|}{ Paraparesis, $n=20$} & \multicolumn{2}{|c|}{ Total, $n=35$} \\
\hline & Number & \%age & Number & $\%$ age & Number & $\%$ age \\
\hline ATM & 10 & 28.57 & 14 & 40 & 24 & 68.57 \\
\hline SACD & 2 & 5.71 & 3 & 8.57 & 5 & 14.29 \\
\hline MS & 1 & 2.86 & 3 & 8.57 & 4 & 11.43 \\
\hline ADEM & 1 & 2.86 & 0 & 0 & 1 & 2.86 \\
\hline Total & 15 & 42.86 & 20 & 57.14 & 35 & 100 \\
\hline
\end{tabular}

MS: Multiple sclerosis, SCAD: Subacute combined degeneration, ADEM: Acute disseminated encephalomyelitis

show the occurrence to vary from $20 \%$ to $30 \%$. Most of the tumors in the present study were intradural extramedullary comprising meningioma $(\mathrm{n}=4)$ and neurofibroma $(\mathrm{n}=2)$ and rest were intramedullary comprising ependymoma $(\mathrm{n}=2)$ and secondaries $(\mathrm{n}=1)$ which show similarity with the study of Kumar et al. [16].

Detection of bone marrow metastases was done by T1WI and STIR picked up more marrow lesions. On MRI, neurofibroma was seen as fusiform lesion with low to intermediate intensity on T1WI and high signal on T2WI. Studies have shown that MR imaging has a significant impact on spinal tumor evaluation.

ATM ( $n=24,68.57 \%)$ was found to be the major cause of non-traumatic non-compressive myelopathy in our study. In the study conducted by Chaurasia et al., 35 cases of ATM accounted for the majority of the cases in non-compressive group. Out of 24 patients, 10 (41.66\%) patients showed quadriparesis and $14(58.33 \%)$ patients showed paraparesis in the present study. Sixteen (66.67\%) patients had a specific sensory level and 14 (58.33\%) patients had bladder-bowel involvement. In Chaurasia et al. study, 17 cases had quadriparesis and 18 had paraparesis. Huh et al. [17] found bowel dysfunction in 9 (19.6\%) patients, motor deficit in $71.7 \%$, sensory deficit in $45(97.8 \%)$ patients, and urinary dysfunction in 25 (54.3\%) patients. Similar findings were there with Haleem et al. study, where 24 (92.3\%) cases presented with paraparesis, $20(77 \%)$ cases had a specific sensory level, and bowel and bladder involvement in $15(60 \%)$ cases. ATM has been described as a longitudinal myelitis involving multiple segments, whereas MS plaques are more focal and involve only 1-2 segments [18]. MRI of 22 patients in the present study showed spinal cord edema and hyperintense $\mathrm{T} 2 \mathrm{~W}$ signals affecting a large part of the cord.

Out of five patients of SACD, two had quadriparesis and three had paraparesis. The diagnosis was confirmed by finding of macrocytic red cells and a low serum Vitamin B-12 concentration. MRI showed bilateral symmetrical hyperintense signal of dorsal column on T2W. In the study of Chaurasia et al., T2 hyperintense signal was most commonly seen in posterior and lateral column in both cervical and thoracic region of cord.

MS was the third most common cause in non-compressive myelopathy group. Three patients had paraparesis and one had quadriparesis. MRI findings of brain showed multiple high signal lesions seen, particularly in the periventricular region on T2 image.

The other etiologies of our study were found to be syringomyelia, multiple myeloma, ADEM, and HIV myelopathy with a very few numbers of cases.

The major limitations of our study population are its smaller sample size and hence the results cannot be generalized to the whole population of non-traumatic myelopathy.

MRI depicts the spinal cord directly, assesses its contour and internal signal intensity characteristics reliably and non-invasively so we can evaluate associated cord edema or contusion and also the integrity and early changes in intervertebral discs and ligaments which can be crucial in long-term prognosis of the patients [16].

\section{CONCLUSION}

Pott's spine and spondylotic myelopathy were the most common etiologies of non-traumatic compressive myelopathy and ATM was the most important etiology in the non-compressive group. MRI has proven to be the ultimate imaging modality for their etiological evaluation.

\section{AUTHORS' CONTRIBUTIONS}

The authors declare that all the named authors have contributed equally to this article.

\section{CONFLICTS OF INTEREST}

The authors have no conflicts of interest to disclose.

\section{REFERENCES}

1. Seidenurum DJ. Myelopathy. AJNR Am J Neuroradiol 2008;29:1032-4.

2. Ginsberg L. Disorders of the spinal cord and roots. Pract Neurol 2011;11:259-67.

3. de Rezenda Pinto WB, Sgobbi de Souza PV, Cristino de Albuquerque MV, Dutra LA, Pedroso JL, Barsottini OGP. Non traumatic myelopathies. Arq Neuropsiquiatr 2016;74:161-5.

4. Granados AM, Garcia L, Ortega C, Lopez A. Diagnostic approach to 
myelopathies. Rev Colomb Radiol 2011;22:1-21.

5. Arjunprakash, Poojary SR, Ranganath R, Vedaraju KS. Evaluation of non-traumatic myelopathy using magnetic resonance imaging. IJRDI 2020;3:270-6.

6. Kent DL, Haynor DR, Longstreth JR, Larson EB. The clinically efficacy of magnetic resonance imaging in neuroimaging. Ann Intern Med 1994;120:856-71.

7. Vaishnav B, Suthar N, Modi D. Acute non-traumatic paraparesis: A comprehensive analysis of aetiology and clinical profile in an Indian subpopulation. NJIRM 2014;5:17-21.

8. World Health Organization, International Spinal Cord Society. International Perspectives on Spinal cord Injury. Geneva: World Health Organization; 2013. p. 11-32

9. Haleem MA, Islam MS, Quraishi FA, Hossain S, Gosh LC, Wadud MS, et al. MRI based evaluation of the etiology of non-traumatic myelopathies in Bangladesh. JNIN Bangladesh 2018;4:87-91.

10. Chaurasia RN, Verma A, Joshi D, Mishra S. Etiological spectrum of non-traumatic myelopathies: Experience from a tertiary care centre. JAPI 2006;54:445-8.

11. Joshi BR. Role of MRI in non-traumatic paraparesis and tetraparesis. Austin J Radiol 2015;2:2-4.
12. Yadav RK, Agarwal S, Saini J. Profile of compressive myelopathy as evaluated by magnetic resonance imaging. J Indian Med Assoc 2008;106:79-82.

13. Deivigan P, Ranjan RK, Toppo SK, Kumari R, Kumar V. Etiological spectrum of non-traumatic myelopathies in adults using MRI at a tertiary care hospital in Jharkhand. JMSCR 2018;6:848-53.

14. Jung NY, Jee WH, Ha KY, Park CK, Byun JY. Discrimination of tuberculous spondylitis from pyogenic spondylitis on MRI. AJR Am J Roentgenol 2004;182:1405-10.

15. Nagata K, Ohasi J, Abe J, Morita M, Inone A. Cervical myelopathy in elder patients: Clinical results and MRI findings before and after decompression surgery. Spinal Cord 1996;34:220-6

16. Kumar S, Suman S, Singh GN. Evaluating the causes of compressive myelopathy by MRI in PMCH, Patna. Panacea J Med Sci 2020;10:152-7.

17. Huh Y, Park EJ, Jung JW, Oh S, Choi SC. Clinical insights for early detection of acute transverse myelitis in the emergency department. Clin Emerg Med 2015;2:44.

18. Bakshi R, Kinkel PR, Mechtler LL, Bates VE, Lindsay BD, Esposita SE, et al. Magnetic resonance imaging findings in 22 cases of myelitis: Comparison between patients with and without multiple sclerosis. Eur J Neurol 1998;5:35-48. 